\title{
Geometry and iPads in Primary Schools: Does their Usefulness Extend Beyond Tracing an Oblong?
}

\author{
Kevin Larkink.larkin@griffith.edu.au \\ Griffith University \\ AUSTRALIA
}

\begin{abstract}
Although research into the use of mathematics apps in classrooms is becoming more common, robust research into Geometry apps is still in its infancy. Such research is particularly necessary in the case of Geometry apps where accurate and dynamic representations are critical in enhancing mathematical learning. This chapter begins to address the lack of research in this domain and presents findings from a qualitative and quantitative analysis of 53 Geometry apps initially selected from a broader range of apps available at the iTunes App Store. These findings indicate that the majority of the 53 apps were limited in their ability to assist students in developing Geometrical conceptual understanding. While this is of concern to educators, there are a small number of Geometry apps which would be most useful in teaching Geometry to primary aged students.
\end{abstract}

\section{Introduction}

This chapter synthesizes the research literature concerning the use of virtual manipulatives in mathematics education and then outlines a four-step methodology for evaluating the appropriateness of Geometry apps. Research such as this is needed as there has been little to no specific research into their usefulness in developing Geometry concepts. In addition, where research has been conducted into mathematical apps, with a few exceptions (Larkin, 2013; 2014; 2015; Moyer-Packenham, et al., 2014), such research has largely been descriptive in nature. Findings of this research indicate that, although the majority of the iPad Geometry apps utilized external representations, most were limited in assisting students in developing deepened conceptual understanding of primary-level Geometry concepts.

For the purpose of this chapter, Geometry apps are those that include content applicable to primary schooling (5-12 year olds) including 1D lines, 2D shapes, 3D objects, transformations, co-ordinate geometry, angles and symmetry. Determining the quality of an app is difficult not only due to a lack of current research, but also because the information that is available at the iTunes App Store is supplied by the app developer and largely serves as an infomercial. The problem of determining quality in relation to Geometry is compounded by the fact that Geometry apps are much more likely to require accurate external representations. Consequently a new methodology for evaluating the usefulness of Geometry apps was designed.

The focus of this chapter is an explanation of how the constructs of pedagogical, mathematical and cognitive fidelity (Dick, 2008), the Haugland (1999) developmental scale, and a modified version of Bos' (2009) software game format were used to evaluate 53 Geometry apps. The goals of this chapter are two-fold. The first goal is to articulate a methodology for reviewing the apps such that other teachers or researchers can use the methodology to review Geometry apps as they become available. The second goal is the creation of a web-based database of Geometry apps, categorized according to how well they promote conceptual understanding in Geometry. This research recognizes that the choice and use of Geometry apps needs to be based on a deep understanding of the pedagogical, mathematical and cognitive strengths and weaknesses of the apps.

\section{Literature Review}

Research into the use of concrete manipulatives in mathematics is extensive and only indicative research is included below. Carbonneau, Marley, and Selig (2013) synthesize the 
findings of decades of research in suggesting that concrete manipulatives support the development of abstract reasoning, stimulate the real-world knowledge of learners, provide opportunities for enactment of concepts, and encourage learner-driven exploration of such concepts. Burns and Hamm (2011) indicate that students engaged in extensive use of concrete manipulatives at the early elementary levels of schooling consistently outperform students with limited to no access to such materials. Suh and Moyer (2007) argue that

the use of manipulatives allows students to make the important linkages between conceptual and procedural knowledge, to recognize relationships among different areas of mathematics, to see mathematics as an integrated whole, to explore problems using physical models, and to relate procedures in an equivalent representation (p. 22).

A contribution to the literature from this chapter is determining whether or not this is the case with iPad-based Geometry manipulatives. As Geometry apps rely heavily on virtual representations, it is informative to examine research related to computer-based manipulatives as touch-screen devices are likely to replicate many of the features of computer-based manipulatives in relation to external representations and physical interactions (Manches \& O’Malley, 2012).

\section{Definitions and Findings Concerning Virtual Manipulatives}

Moyer, Bolyard, and Spikell (2002) define a virtual manipulative as "an interactive, Web-based visual representation of a dynamic object that presents opportunities for constructing mathematical knowledge" (p. 373). Given the interactivity of virtual manipulatives, students can mimic actions applied when manipulating concrete geometric materials and flip, slide or rotate the visual representations as if they were actual 3D objects (Rosen \& Hoffman, 2009). Representations such as these can also be linked to symbolic notations so that concept development can be enhanced. Moyer-Packenham and Westenskow (2013) suggest that virtual manipulatives are designed to "connect pictorial representations, actions performed on them, and symbolic representations, to highlight mathematical concepts and focus the attention of the learner on the mathematics to be learned" (p. 37). For instance, they can link different forms of representation, such as symbolic, pictorial and concrete (e.g., a diagram depicting the area of a rectangle along with the formula $\mathrm{A}=\mathrm{L} * \mathrm{~W}$ ), or link different representational models to each other (e.g., a set model to a region model both representing $1 / 4)$.

Research conducted into the use of computer-based virtual manipulatives confirms many of the positive outcomes of using concrete manipulatives. For example, Clements and Battista (1992) found that student ideas about shapes were more precise and mathematically robust after using the computer-based Logo software. Studies where virtual manipulatives were used showed positive gains in students' conceptual understanding (Reimer \& Moyer, 2005). Highfield and Mulligan (2007) confirmed that virtual manipulatives and dynamic interactive software were powerful mathematical tools in aiding student concept development. Moyer-Packenham and Westenskow (2013) found that virtual manipulatives have a moderate effect on student achievement (when compared against other instructional treatments) and suggest that virtual manipulatives "have unique embodiments that have positive impacts on student achievement in mathematics" (p. 46). Özel (2012) reports on some of the affective effects of the use of virtual manipulatives and notes that immediate feedback enhanced student self-efficacy.

In contrast, a number of researchers have cautioned against considering virtual manipulatives as a panacea for the much publicized woes of mathematics education. One set 
of concerns relates to the technological aspects of virtual manipulatives. Chang, Yuan, Lee, Chen, and Huang (2013) suggest that the computer skills required to use virtual manipulatives can be problematic, particularly for younger students who may require significant teacher scaffolding. In addition, the use of virtual manipulatives can be distracting to some students as activities not necessarily related to mathematics are only a click away. Perhaps of greater concern is the mathematics underpinning some of the virtual manipulatives, as it cannot be automatically assumed that the use of virtual manipulatives will bring about mathematical understanding. Uribe-Flórez and Wilkins (2010) remind us that the value of virtual manipulatives lies in their ability to promote the quality of student thinking and in the extent to which their external representations assist students to generate mathematical abstractions. These may be limited for some students who are deprived of the tactile experience of concrete manipulatives and who may thus not develop conceptual understanding as richly as might be possible with concrete materials (Chang et al., 2013). Moyer-Packenham and Westenskow's (2013) meta-analysis results also show that while virtual manipulatives have a moderate effect overall in student achievement, these effects are inconsistent across student age levels and mathematics content being taught. This suggests that a large range of contextual features need to be considered before using virtual manipulatives - for example, prior experience with computers, age, and content versus concept development. This point is supported by Uribe-Flórez and Wilkins (2010) who noted that "how teachers design their classroom activities involving manipulatives will ultimately affect the success of their use on student understanding" (p. 364). Regardless of past findings concerning the use of virtual manipulatives, it is clear that further research is required, particularly with the increasing availability of the iPad as a tool for mathematics education. The following section of the literature review concludes with a discussion on three aspects of fidelity in relation to apps, namely, pedagogical, mathematical, and cognitive fidelity (Dick, 2008) and outlines how they were incorporated into a methodology for evaluating apps.

\section{Pedagogical, Mathematical and Cognitive Fidelity}

Pedagogical fidelity is defined by Dick (2008) as the degree to which a student can use a tool to further their learning. Zbiek, Heid, Blume and Dick (2007) suggest that pedagogical fidelity also refers to "the extent to which teachers (as well as students) believe that a tool allows students to act mathematically in ways that correspond to the nature of mathematical learning that underlies a teacher's practice" (p. 1187). Dick suggests that a pedagogically faithful tool will likely be described by students in terms of how it allowed them to interact with mathematics (e.g." "I created this triangle" etc.) rather than simply as a description of procedures for use (e.g. "I set the preferences to fast" etc.). Therefore, to be an effective pedagogical tool, an app must support any action by the student that will lead to conceptual understanding of the underpinning mathematical principle.

The second of the three fidelities used to evaluate the apps is mathematical fidelity. Zbiek et al. (2007) define this as the "faithfulness of the tool in reflecting the mathematical properties, conventions, and behaviors (as would be understood or expected by the mathematical community)" (p. 1173). Thus, mathematical fidelity is present when the activity of a student is "believable, is concrete, and relates to how mathematics is a functional part of life" (Bos, 2011, p. 171) and when they add strength to an understanding of mathematics as a language of patterns and order. Dick (2008) cautions, however, that the current drive for user friendliness can sometimes run contrary to mathematical fidelity. This is particularly worrisome in relation to apps as many apps are designed by non-educators for financial profit. Keeping the notion of mathematical fidelity at the forefront of decisions when selecting apps reminds teachers to avoid apps that do not deliver accuracy in terms of mathematical content or constructs, for example, incorrect scaling in transformations. 
The third of the elements in evaluating apps is cognitive fidelity, which refers to "the faithfulness of the tool in reflecting the learner's thought processes or strategic choices while engaged in mathematical activity" (Zbiek et al., 2007, p. 1173). Cognitive fidelity can be viewed largely in terms of the external representations provided by the tool and Zbiek et al. argue that "if the external representations afforded by a cognitive tool are meant to provide a glimpse into the mental representations of the learner then the cognitive fidelity of the tool reflects the faithfulness of the match between the two" (p. 1176). This notion of cognitive fidelity is obviously very important in Geometry apps which are likely to utilize many external representations. The virtual nature of app objects does allow for high degrees of cognitive fidelity; for example, 3D objects can be pulled apart and put back together, and in so doing, can reinforce the link between 3D objects and their 2D representations (i.e., nets).

\section{Learnings from the Literature}

It is clear from the literature that manipulatives play a special role in mathematical activity. Although external representations can never exactly represent students' internal mental representations, they are useful as "visible phenomena that can be shared and discussed with others (e.g., other learners or the teacher)" (Zbiek, Heid, Blume, \& Dick, 2007, p. 1173). However, despite positive findings, use of manipulatives by teachers is inconsistent. Reasons offered by some teachers for their lack of use include lack of time to invest in locating virtual resources, particularly those that promote mathematical understanding rather than just rote learning (Calder, 2015), as well as a misunderstanding that manipulatives will, in themselves, do the teaching for them (Puchner, Taylor, O'Donnell \& Fick, 2008). This may be because teachers tend to use manipulatives, including virtual manipulatives, in a procedural or declarative manner rather than using them to enhance conceptual development.

Although an understanding of the three types of fidelity can assist teachers in making decisions about whether or not to use apps, it is argued above that one problem for teachers is the lack of time to evaluate apps using the three fidelities (or indeed any other evaluative process). In addition, although it might be expected that some of the findings on the use of virtual manipulatives may reflect the experience of using mathematics apps, apart from a few exceptions (Larkin, 2014, 2015; Moyer-Packenham et al., 2014), rigorous quantitative research into Geometry apps is in its infancy and thus further research is required.

Two research questions guided this research:

1. Are the Geometry apps currently available at the iTunes store appropriate for enhancing the learning of Geometry in primary mathematics?

2. Is the methodology utilized in this research robust in terms of internal consistency and also in its "user friendliness" such that teachers and researchers can be confident in using it to evaluate new Geometry apps as they become available?

\section{Methodology}

This section will outline the process for initially finding the Geometry apps, explain how three quantitative measures were used to evaluate the apps, and discuss measures of internal coherence and inter-reliability that were deployed to maximise the accuracy of the evaluations. Teachers can also refer to the dataset generated by this research to assist them in selecting what the author considers as highly appropriate Geometry apps.

\section{Locating the Apps}

The evaluation process for this research commenced with a targeted search for Geometry apps at the iTunes App Store in October, 2014. The following search terms were used Geometry Elementary Education, Geometry Junior Education, Geometry Primary Education, 
Symmetry Education and Transformations Education. Many of the same apps appeared in two or more of the searches. To generate a workable sample size, apps were excluded from the final review according to the following criteria.

- If both a free version and a paid version (these present as two different apps) were available, both versions were reviewed only if this were necessary to evaluate the app accurately

- Where there were a number of apps in a series, only one app was reviewed as the apps in a series share similar structural and pedagogical properties

- Although the author recognises that mathematics learning occurs via games (see Beavis, Muspratt \& Thompson, 2015) apps that were categorized by iTunes as Games, Entertainment or Lifestyle, rather than categorised as Education, were excluded from the sample

- Apps where mathematics was part of a bigger package of reading, writing, and spelling skills were excluded

- Apps that required additional costs for access or further online registration of students or teachers were excluded

Although a sample of the apps were also evaluated by other mathematics educators, the author was primarily responsible for generating the scores. The scores are based on the author's experience of primary school mathematics for the past 30 years and also on the findings of his doctoral research exploring the use of technology in primary school classrooms. The author extensively interacted with each app until a decision could be made about its quality. It is also acknowledged that these reviews are subjective and also that the reviews rapidly go out of date. The author is currently working with primary educators in a range of schools to correlate the review findings with the experience of classroom teachers who have used the apps. In addition, teachers have been invited, via communication through professional mathematics organisations, to contribute to the reviews so that the site remains current.

Scoring of the apps involved the use of a two-page score sheet (see Appendix). This scoresheet included a qualitative review of the apps which was later transferred to a Google document available to teachers at the link provided later in this chapter. This qualitative review included year-level appropriateness, Australian Curriculum content covered, and a general comment regarding the usefulness of the app. The scoresheet also used a series of measures for scoring the apps; the Haugland (1999) development scale, Bos' (2009) six software formats, and Dick's (2008) three measures of fidelity. These three measures were used as they respectively evaluate the appropriateness of the apps for student use, their appropriateness as virtual manipulatives in general, and then more specifically their usefulness in developing mathematical understanding.

\section{Haugland Scale - Background and Process}

The Haugland software developmental scale (adapted for this research in Table 1) is a criterion-based tool used to evaluate the appropriateness of web-based applications and software for use by children (Haugland, 1999; Haugland \& Ruiz, 2002).

Table 1

Adapted Haugland Developmental Software Scale with Clusters and Elaborations

\begin{tabular}{|l|l|l|}
\hline Cluster & Criteria & Criteria elaboration with links to mathematics \\
\hline & $\begin{array}{l}\text { Age } \\
\text { Appropriate }\end{array}$ & $\begin{array}{l}\text { The mathematics concepts taught by the app reflect } \\
\text { realistic expectations for the age children for which it was } \\
\text { designed. }\end{array}$ \\
\cline { 2 - 3 } Child-Centred & Child Control & $\begin{array}{l}\text { When using the app, children decide the flow and direction } \\
\text { for the experience, not the device. They are navigators, }\end{array}$ \\
\hline
\end{tabular}




\begin{tabular}{|c|c|c|}
\hline \multirow[t]{3}{*}{ (4 points possible) } & & $\begin{array}{l}\text { determining where the experience will lead and learn the } \\
\text { consequences of their choices. }\end{array}$ \\
\hline & Independence & $\begin{array}{l}\text { While adults may need to assist children in loading the } \\
\text { application, after this initial guidance and support, children } \\
\text { operate the app with minimal adult supervision. }\end{array}$ \\
\hline & Non-violence & $\begin{array}{l}\text { Violence in apps is of particular concern because children } \\
\text { often initiate and control the violence. In addition, the app } \\
\text { models appropriate societal values. }\end{array}$ \\
\hline \multirow{3}{*}{$\begin{array}{l}\text { Design of App } \\
\text { ( } 3 \text { points possible) }\end{array}$} & $\begin{array}{l}\text { Clear } \\
\text { Instructions }\end{array}$ & $\begin{array}{l}\text { Verbal instructions are essential, since even children who } \\
\text { are reading text-based instructions navigate with greater } \\
\text { success if audio instructions are also provided. Directions } \\
\text { are accompanied with visual prompts and/or a help option. }\end{array}$ \\
\hline & $\begin{array}{l}\text { Technical } \\
\text { Features }\end{array}$ & $\begin{array}{l}\text { The app is colorful with realistic uncluttered graphics, } \\
\text { which enable children to focus on the learning objectives. } \\
\text { Graphics are animated to help children attend. Whenever } \\
\text { possible children control the animation, learning } \\
\text { mathematics through hands-on experiences. }\end{array}$ \\
\hline & $\begin{array}{l}\text { Real World } \\
\text { Model }\end{array}$ & $\begin{array}{l}\text { The app provides children with concrete representations of } \\
\text { objects found in meaningful and mathematically accurate } \\
\text { situations or settings. The scale and color of the objects are } \\
\text { realistic, not stereotypical. }\end{array}$ \\
\hline \multirow{3}{*}{$\begin{array}{l}\text { Learning App } \\
\text { ( } 3 \text { points possible) }\end{array}$} & $\begin{array}{l}\text { Expanding } \\
\text { Complexity }\end{array}$ & $\begin{array}{l}\text { The app is an exciting world that is easy for children to } \\
\text { enter and reflects children's current cognitive, physical, } \\
\text { mathematical and language skills. When children use the } \\
\text { application a logical, mathematical learning sequence } \\
\text { emerges. }\end{array}$ \\
\hline & $\begin{array}{l}\text { Process } \\
\text { Orientation }\end{array}$ & $\begin{array}{l}\text { Intrinsic motivation; the desire to explore and experiment } \\
\text { and discover mathematics motivates children as they use } \\
\text { the app, not rewards. The joy of learning is the reward in } \\
\text { using the app. }\end{array}$ \\
\hline & Transformations & $\begin{array}{l}\text { Apps have the unique potential to give children } \\
\text { opportunities to change objects and situations over and } \\
\text { over and discover how different mathematical components } \\
\text { impact their world. }\end{array}$ \\
\hline
\end{tabular}

The Haugland scale was not initially designed to evaluate mathematical apps. Consequently, two important modifications were made for this research. First, in order to analyze the data more thoroughly, the original 10 criteria were grouped into three sub-clusters (child-centered, design features, and learning features). Second, elaborations were added to the sub-indicators to emphasize the relationship of the apps to mathematics. In scoring the apps, each of the 10 criteria is worth one point and each app can thus score between 0 and 10 . The scoring sheet includes a number of sub-indicators for each criterion. For apps to score a 1 for each criterion they must meet all relevant sub-indicators. If they meet $50 \%$ or more of the indicators a score of 0.5 is recorded and if less than $50 \%$ are met a score of 0 is recorded. For example, there are three sub-indicators in the Process Orientation criterion. If an app demonstrated all three indicators, a score of 1 was allocated; if two of the three indicators were demonstrated, a score of 0.5 was allocated; if one or none of the indicators were demonstrated, a score of 0 was allocated. A nominal rather than absolute level of scoring was used in this scale as there are differing numbers of indicators across the ten criteria.

\section{Bos' Game Format - Modification for this Research and Scoring Criteria}

It is important, in terms of student learning and student engagement, that teachers can efficiently and accurately make an accurate evaluation of the type (format) of app they are considering using. The work of Bos (2009) is adapted in this research to evaluate the format of Geometry apps. Bos categorized computer software into six formats: static tools, 
informationals, quizzes/tests, drill and practice games, virtual manipulatives (VM), and interactive maths objects (IMO). Bos' research suggested that the format greatly influences the level of fidelity present in the virtual resource. For example, static tools that generate results in symbolic or graphic representations are likely to inhibit deeper abstraction or generalizations, whereas VM, which engage students in mathematical activity, are likely to make abstract concepts more concrete and thus can be a stepping stone to a deepened conceptual understanding (Bos, 2009). Table 2 presents a brief summary of the six formats and an indication of their purpose, strengths, and weaknesses in relation to Geometry apps. In terms of the evaluation in this research, apps which were static tools scored 1 point, informationals scored 3 points, quizzes/tests scored 4 points, drill and practice games scored 6 points, VM scored 8 points, and IMO scored 10 points.

Table 2

Possible App Formats and their Strengths / Weaknesses (Adapted from Bos, 2009)

\begin{tabular}{|c|c|c|c|}
\hline Format of App & Purpose & Strengths & Weaknesses \\
\hline $\begin{array}{l}\text { Static Tool } \\
\text { (Scientific } \\
\text { Calculator App) }\end{array}$ & $\begin{array}{l}\text { Uses calculators or } \\
\text { function machines to } \\
\text { process inputs. }\end{array}$ & $\begin{array}{l}\text { Useful for generation and } \\
\text { / or display of data in } \\
\text { form of tables, charts, } \\
\text { graphs etc. }\end{array}$ & $\begin{array}{l}\text { Are discrete pieces of } \\
\text { information and require } \\
\text { conceptual understanding } \\
\text { for sense making. } \\
\text { Primarily descriptive } \\
\text { rather than interpretive. }\end{array}$ \\
\hline $\begin{array}{l}\text { Informational } \\
\text { (E.G. Basic } \\
\text { Geometry) }\end{array}$ & $\begin{array}{l}\text { Used to convey technical } \\
\text { and procedural } \\
\text { information. Used for } \\
\text { direct instruction }\end{array}$ & $\begin{array}{l}\text { Can provide useful } \\
\text { information for students. } \\
\text { Clear, logical format. }\end{array}$ & $\begin{array}{l}\text { Provides facts but often } \\
\text { lacks connectivity to } \\
\text { other concepts. Limited to } \\
\text { no conjectures or problem } \\
\text { solving. }\end{array}$ \\
\hline $\begin{array}{l}\text { Quizzes / Tests } \\
\text { (E.G. Angle } \\
\text { Game) }\end{array}$ & $\begin{array}{l}\text { Used to check for } \\
\text { understanding through } \\
\text { multiple-choice, short } \\
\text { fill-in-the-blank, and } \\
\text { true/false questions. }\end{array}$ & $\begin{array}{l}\text { Useful for checking } \\
\text { procedural understanding } \\
\text { and recall. More useful if } \\
\text { error correction occurs. }\end{array}$ & $\begin{array}{l}\text { Focus on recall may not } \\
\text { facilitate sense making. } \\
\text { Focus is on correctness } \\
\text { rather than process. }\end{array}$ \\
\hline $\begin{array}{l}\text { Drill \& Practice } \\
\text { Games } \\
\text { (E.G. } \\
\text { Geometry4Kids) }\end{array}$ & $\begin{array}{l}\text { Used for practicing a skill } \\
\text { and can be highly } \\
\text { motivational for the } \\
\text { competitive student. }\end{array}$ & $\begin{array}{l}\text { Motivational - students } \\
\text { like to play games - } \\
\text { useful for declarative } \\
\text { knowledge }\end{array}$ & $\begin{array}{l}\text { Often don't contribute to } \\
\text { the understanding of a } \\
\text { concept. Winning can be } \\
\text { the aim with mathematics } \\
\text { learning secondary. }\end{array}$ \\
\hline $\begin{array}{l}\text { Virtual } \\
\text { Manipulatives } \\
\text { (Symmetry } \\
\text { Draw) }\end{array}$ & $\begin{array}{l}\text { Used to demonstrate a } \\
\text { conceptual understanding } \\
\text { of a mathematical idea. } \\
\text { Require detailed } \\
\text { instructions and teacher } \\
\text { monitoring. }\end{array}$ & $\begin{array}{l}\text { Very useful for } \\
\text { encouraging modelling of } \\
\text { mathematics. Can } \\
\text { supplement concrete } \\
\text { manipulative already in } \\
\text { use. }\end{array}$ & $\begin{array}{l}\text { Often require a great deal } \\
\text { of teacher assistance. } \\
\text { May not always be } \\
\text { accurate representations. }\end{array}$ \\
\hline $\begin{array}{l}\text { Interactive } \\
\text { Maths Objects } \\
\text { (Geometry 2D } \\
\text { Pad) }\end{array}$ & $\begin{array}{l}\text { Uses multiple } \\
\text { representations that are } \\
\text { interactive and change } \\
\text { with the given input. In } \\
\text { this format, patterns can } \\
\text { be observed and } \\
\text { manipulated. }\end{array}$ & $\begin{array}{l}\text { Encourages the } \\
\text { investigation of } \\
\text { mathematics patterns } \\
\text { which emerge intuitively. }\end{array}$ & $\begin{array}{l}\text { May not be easy to create } \\
\text { maths objects for all } \\
\text { mathematics concepts. }\end{array}$ \\
\hline
\end{tabular}

\section{Three Fidelities Score Sheet - Creation and Scoring Criteria}

The final measure used in determining the quality of the Geometry apps is an evaluative tool created for this research (see Table 3), based on Dick's (2008) three fidelities. 
The three dimensions of pedagogical (including technological), mathematical and cognitive fidelity have been used by other researchers to determine the quality of mathematics manipulatives (e.g. Bos, 2009; Zbiek et al., 2007). Bos (2009) went some way towards using the dimensions as a form of quantitative assessment by creating a table of the three fidelities and indicating what a low, medium, or high level of each dimension may look like in relation to computer software. What has not been done previously is the assigning of a numerical value to represent the degree, along a continuum, to which these three dimensions are present in software in general, let alone more specifically in Geometry apps.

Table 3

Levels of Fidelity in Apps - Adapted from Bos (2009)

\begin{tabular}{|c|c|c|c|}
\hline Type of Fidelity & Low Level (1-3) & Medium Level (4-7) & High Level (8-10) \\
\hline $\begin{array}{l}\text { Pedagogical } \\
\text { (Including } \\
\text { Technological) } \\
\text { The degree to } \\
\text { which the App } \\
\text { can be used to } \\
\text { further student } \\
\text { learning. }\end{array}$ & $\begin{array}{l}\text { App is difficult to work } \\
\text { with. Accessing all } \\
\text { aspects of the app is } \\
\text { difficult. App is not } \\
\text { appropriate for the } \\
\text { mathematics concepts it } \\
\text { uses. Transitions are } \\
\text { inconsistent or illogical. }\end{array}$ & $\begin{array}{l}\text { Using App is not initially } \\
\text { intuitive; but with } \\
\text { practice becomes so. } \\
\text { Mathematical activities } \\
\text { presented are appropriate } \\
\text { but could be developed } \\
\text { without app. Transitions } \\
\text { evident but only made } \\
\text { via trial \& error. }\end{array}$ & $\begin{array}{l}\text { Manipulation of App is } \\
\text { intuitive \& encourages } \\
\text { user participation. } \\
\text { Little or no training or } \\
\text { instructions are required } \\
\text { Transitions are logical \& } \\
\text { aid sense making. }\end{array}$ \\
\hline $\begin{array}{l}\text { Mathematical } \\
\text { The degree to } \\
\text { which the App } \\
\text { reflects } \\
\text { mathematical } \\
\text { properties, } \\
\text { conventions and } \\
\text { behaviors. }\end{array}$ & $\begin{array}{l}\text { Mathematical concepts } \\
\text { are underdeveloped or } \\
\text { overly complex. Lack of } \\
\text { patterns. Lack of } \\
\text { connection to real world } \\
\text { mathematics. }\end{array}$ & $\begin{array}{l}\text { Application of } \\
\text { mathematics concepts } \\
\text { unclear. Patterning is } \\
\text { evident but lacks } \\
\text { predictability or is } \\
\text { unclear. Some } \\
\text { connection to real world } \\
\text { mathematics. }\end{array}$ & $\begin{array}{l}\text { Mathematics concepts } \\
\text { developed are correct \& } \\
\text { age appropriate. } \\
\text { Patterns are accurate \& } \\
\text { predictable. Clear } \\
\text { connection with real } \\
\text { world mathematics. }\end{array}$ \\
\hline $\begin{array}{l}\text { Cognitive } \\
\text { The degree to } \\
\text { which the App } \\
\text { assists the } \\
\text { learner's thought } \\
\text { processes while } \\
\text { engaged in } \\
\text { mathematical } \\
\text { activity. }\end{array}$ & $\begin{array}{l}\text { No opportunities to } \\
\text { explore or test } \\
\text { conjectures. Static or } \\
\text { inaccurate } \\
\text { representations. Patterns } \\
\text { do not connect with } \\
\text { concept development. }\end{array}$ & $\begin{array}{l}\text { Limited opportunities to } \\
\text { explore or test } \\
\text { conjectures. Minor errors } \\
\text { with representations but } \\
\text { still make sense. Patterns } \\
\text { connect in a limited way } \\
\text { with concept } \\
\text { development. }\end{array}$ & $\begin{array}{l}\text { App encourages } \\
\text { exploration \& testing of } \\
\text { conjectures. } \\
\text { Representations are } \\
\text { accurate \& easily } \\
\text { manipulated. Patterns } \\
\text { clearly aide concept } \\
\text { development. }\end{array}$ \\
\hline
\end{tabular}

In the modified schema an individual app could, for instance, score highly on mathematical fidelity yet poorly on cognitive and pedagogical fidelity. In order to make sophisticated quantitative comparisons, the nominal levels of low, medium and high have been replaced by a continuum ranging from 1 (no fidelity) to 10 (very high fidelity) for each of the three dimensions, resulting in a possible score of 3-30 for overall fidelity. In this manner, the observation that an individual app could score highly on mathematical fidelity yet poorly on cognitive fidelity can be represented numerically to gain a measure of how well or poorly each of the dimensions is represented. In brief, an app is considered low level (1-3) if it is generally static, is inaccurate mathematically, has limited directions, or fails to develop mathematical concepts. It is considered medium level (4-7) if more than one solution is possible, if conjectures are possible (but not testable), and transitions between different aspects of the app are possible but lack clarity. Finally, an app is considered high level (8-10) 
if it uses accurate representations that are easy to manipulate, transitions between app elements are logical and consistent, and multiple conjectures are possible and testable.

Overall, using the three measures above, it is possible for an app to score from 0-10 on the Haugland scale; from 1-10 according to the game format; and from 1-10 on each of the three fidelities: resulting in a total score ranging from 4-50 for overall app quality.

\section{Tests for Internal Coherence}

In order to determine the reliability of the Haugland and fidelities scales, a Cronbach alpha - $\alpha$ was generated for each (see Table 4). A Cronbach alpha score is not appropriate for the Bos format scores. It is generally accepted that Cronbach alpha scores greater than 0.7 indicate a high degree of internal consistency (Muijs, 2011).

Table 4

Cronbach Alpha Reliability Scores for the Two Scales

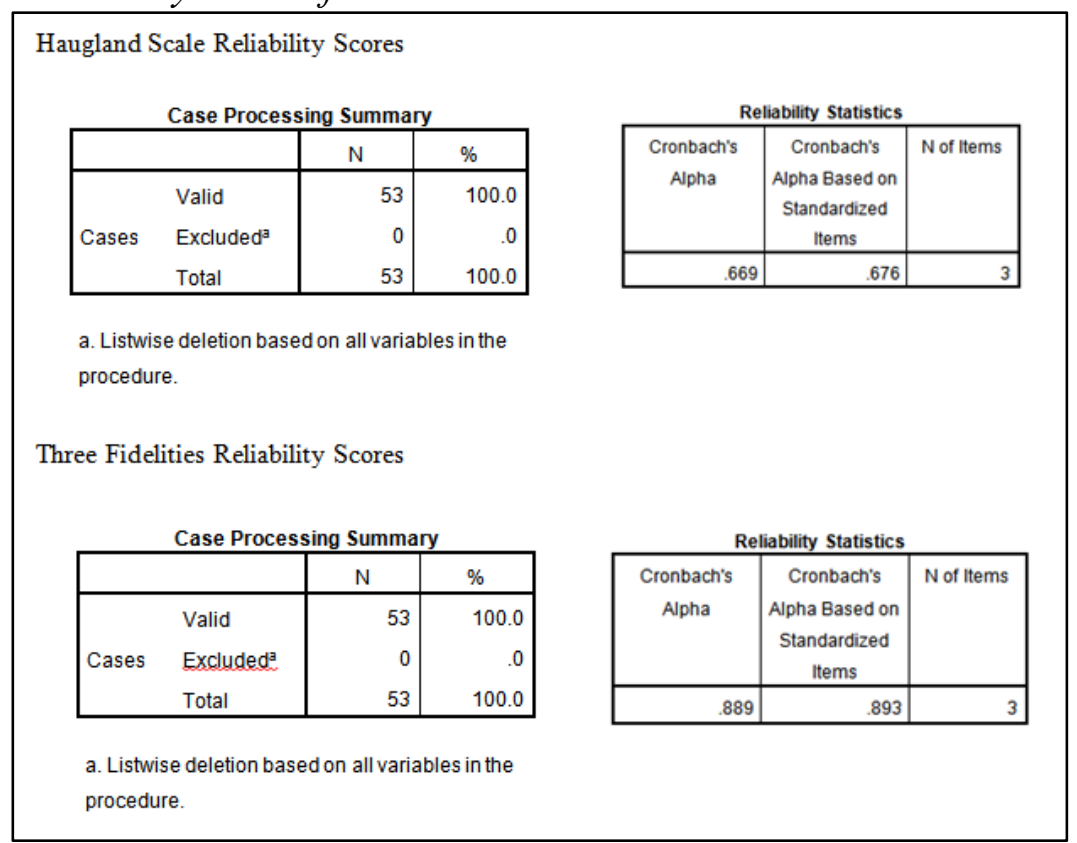

Cronbach's alpha is concerned with the homogeneity of the items that make up the scale (i.e., how well the individual items consistently recognize the same level of quality). In this research, the alpha scores can be viewed in terms of the app's consistency of rating (be that high or low) across the three domains of each of the Haugland sub-clusters (childcentered, design features, and learning features) and the three fidelities (pedagogical, mathematical and cognitive). Although the Haugland scale's alpha score is slightly less than 0.7, previous research (Larkin, 2015) using the Haugland scale reported an alpha score of 0.768 . It may be the case that the alpha score is lower in this research due to a smaller sample of apps $(N=53$ vs $N=142)$ and also due to this research clustering the 10 Haugland criteria, reported in the earlier research, into three sub-clusters. There is thus a high degree of confidence that the two scales are internally consistent and we can therefore be confident in their reliability to determine the quality of an app.

\section{So What Does This Research Tell Us about Geometry Apps?}

Initially finding apps which might be appropriate is not a simple process. Quality apps are difficult to locate due to the sheer number of apps $(160,000$ education apps at the iTunes store (148AppsBiz, 2015) and this difficulty is compounded by naming mismatches or similar naming, the rapid turnover of apps at the store, and a very poor search engine. 
Teachers are extremely time poor and thus are likely to be guided by the description at the iTunes store. These are at best "infomercials" and may often provide misleading details about the app. For all these reasons, educationally robust reviews such as the one available here are critical if teachers are to be directed to find what amounts to a "needle in a haystack" - that is, an app that is appropriate for them to use. As the qualitative component of this research is largely self-explanatory, I include here only one example (see Table 5) of the qualitative information that is available to teachers regarding each of the 53 reviewed apps. Full reviews are available at http://tinyurl.com/Geometry-Apps

Table 5

Example Qualitative Geometry App Review

$\left.\begin{array}{|l|l|l|l|}\hline \text { App name } & \text { Content } & \text { Yr. level } & \multicolumn{1}{c|}{\text { Generic features of the app }} \\ \hline \begin{array}{l}\text { Montessori } \\ \text { Geometry }\end{array} & \begin{array}{l}\text { Shapes } \\ \text { and } \\ \text { Objects }\end{array} & \text { Years F-2 } & \begin{array}{l}\text { Do you remember ever wondering why you were studying } \\ \text { geometry at school? Montessori Geometry was designed to } \\ \text { ensure that your child will never have these doubts. Not } \\ \text { only will this app make him/her realise that geometrical } \\ \text { shapes are everywhere but it will also make him/her proud } \\ \text { to be able to recognise and name them. }\end{array} \\ \hline \begin{array}{l}\text { Reviewer comments re overall quality of app: This app includes } \\ \text { notes for parents / teachers explaining the philosophy and operation of } \\ \text { the app. Glossary includes definitions beyond the early years at which }\end{array} \\ \text { it is targeted - e.g. curvelinear shapes. The app includes dedicated } \\ \text { pages on various 2D shapes and a few 3D objects, sorting activities } \\ \text { feature heavily. User is in control. }\end{array}\right)$

\section{Quantitative Analysis and Discussion}

For ease of analysis, I have combined the findings and discussion into one overall section; however, each of the three measures is presented separately in sub-sections with an overall synthesis of the findings provided at the conclusion of the section.

\section{Process One - Haugland Scale Scores}

Table 6 indicates the apps scoring 7 or more according to the Haugland scale; however, to indicate the quality of all 53 apps, overall mean scores have been included.

Table 6

List of Apps Scoring 7 or More out of 10 on the Haugland Scale

\begin{tabular}{lcccc}
\hline \multicolumn{1}{c}{ Clusters on Haugland scale } & $\begin{array}{c}\text { Child } \\
\text { /4 }\end{array}$ & $\begin{array}{c}\text { Design } \\
\text { /3 }\end{array}$ & $\begin{array}{c}\text { Learning } \\
/ \mathbf{3}\end{array}$ & $\begin{array}{c}\text { Total } \\
/ \mathbf{1 0}\end{array}$ \\
\hline Attribute Blocks & 4 & 2.5 & 2.5 & $\mathbf{9}$ \\
Shapes (MyBlee) & 4 & 2.5 & 2.5 & $\mathbf{9}$ \\
Coordinate Geometry (Ventura) & 4 & 2 & 2 & $\mathbf{8}$ \\
Shapes - 3D Geometry & 3.5 & 2 & 2.5 & $\mathbf{8}$ \\
Shapes and Colors & 4 & 2 & 2 & $\mathbf{8}$ \\
Pattern Shapes & 4 & 2 & 2 & $\mathbf{8}$ \\
Montessori Geometry & 4 & 3 & 1 & $\mathbf{8}$ \\
GeoEng (Patterns) & 4 & 3 & 1 & $\mathbf{8}$ \\
Jungle Geometry & 4 & 3 & 1 & $\mathbf{8}$ \\
Sym Shuffle & 4 & 2.5 & 1.5 & $\mathbf{8}$ \\
Isometry Manipulative & 3.5 & 2 & 2 & $\mathbf{7 . 5}$
\end{tabular}




\begin{tabular}{lcccc} 
Geoboard (Math Learning Centre) & 4 & 2 & 1.5 & $\mathbf{7 . 5}$ \\
Numberkiz Geo & 4 & 1.5 & 2 & $\mathbf{7 . 5}$ \\
Geometry4Kids & 3.5 & 2.5 & 1 & $\mathbf{7}$ \\
Symmetry Draw & 3 & 1.5 & 2.5 & $\mathbf{7}$ \\
Overall Mean for 53 apps & $\mathbf{2 . 8 6}$ & $\mathbf{1 . 6 1}$ & $\mathbf{0 . 9 2}$ & $\mathbf{5 . 4}$ \\
\hline
\end{tabular}

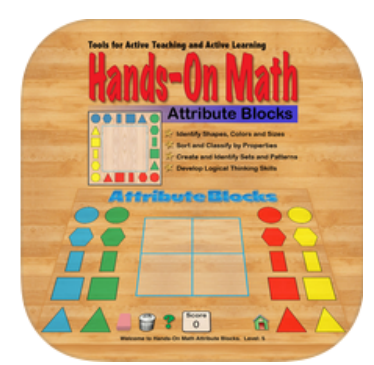

Figure 1. Hands on Attribute Blocks - A top scoring app on Haugland Scale.

Figure 1 shows an example of one of the top scoring apps. The data indicate that the apps were strongest in the child-centred cluster (2.86/4) but weak in the other two clusters (design features 1.61/3; learning features $0.92 / 3$ ) with an overall mean of 5.4/10. These are similar to the findings from earlier research on number and algebra apps (Larkin, 2015) which indicated that the apps were strongest in the child-centered cluster $(2.96 / 4)$ but weak in the other two clusters (design features $1.35 / 3$; learning features $0.69 / 3$ ) with an overall mean of 5.01 .

Further comparisons between these data and the previous data indicate that Geometry apps scored lower overall in the child-centered cluster (2.86 to 2.96) and higher overall in both the design features cluster (1.61 to 1.35 ) and the learning features cluster ( 0.92 to 0.69 ). This likely reflects the fact that the increasing complexity of the Geometry apps, in terms of external representations and the use of symbolic language, makes them less child-centered; however, the trade-off is that more consideration has gone into improving the overall design of the apps with a subsequent, marked increase in their potential to support learning. 


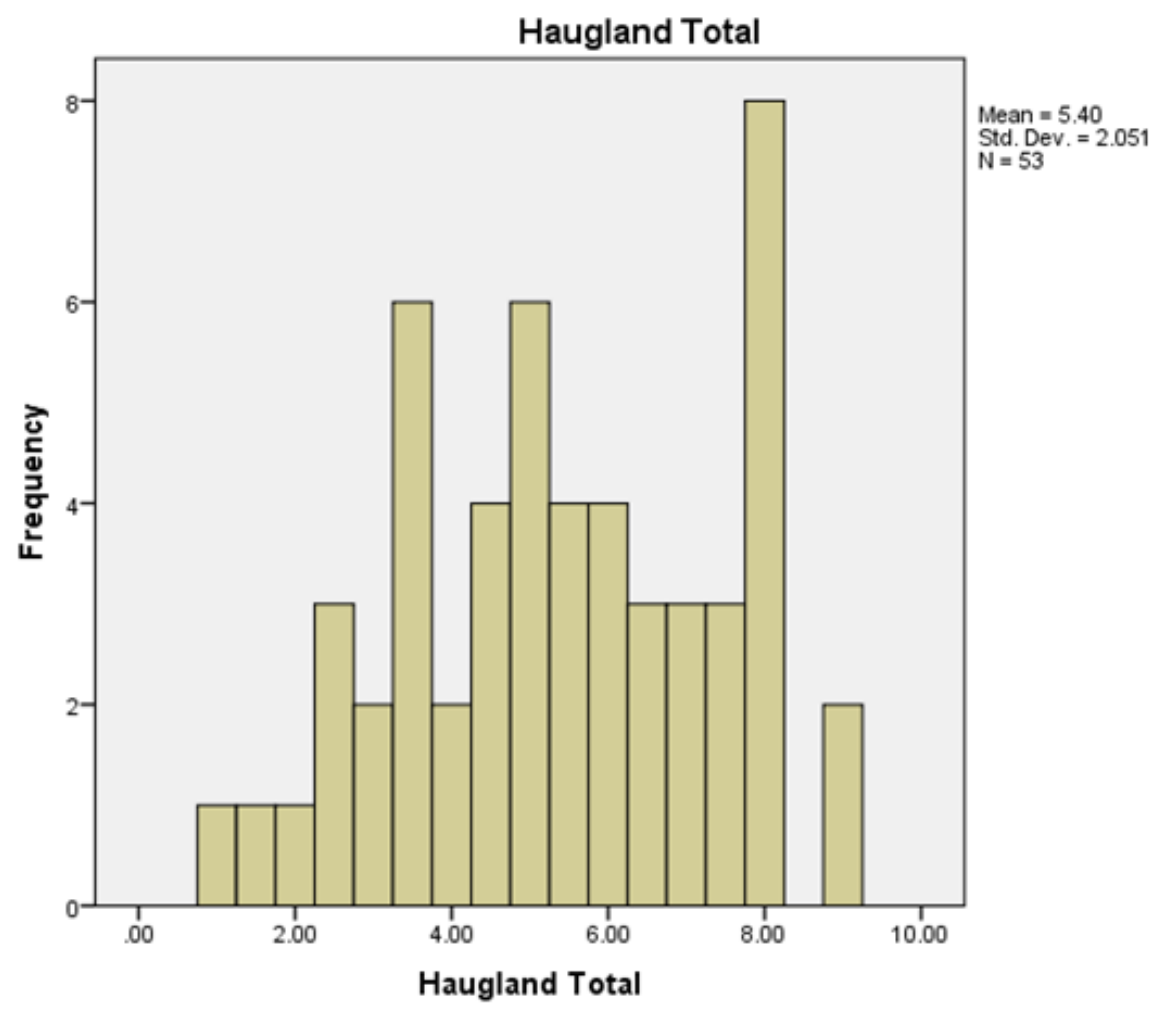

Figure 2. Haugland total scores for 53 apps reviewed.

As can be seen in Figure 2, the spread of scores indicates that there is a large range of quality with roughly half of the apps scoring 5 or less. This is a disappointing result given these are apps advertised in the iTunes store as being both educational and recommended for children of primary school age. As a consequence of these Haugland scale results, the research decision was made that any app scoring less than $50 \%$ on the Haugland Scale is not appropriate to use in primary classrooms, regardless of whether they scored highly in terms of game format or the three fidelities. Of the 53 apps reviewed, 20 apps scored less than 50\% on the Haugland scale, and are therefore considered inappropriate for classroom use. This has implications for the potential use of one of the apps, Geometry 2D pad, which scored exceptionally well in terms of its game format (IMO) and in relation to its mathematics fidelity, but is excluded from the overall list of recommended apps as students are unlikely to be able to engage with the content it provides. Although a score below $50 \%$ renders the app inappropriate, a score of over $50 \%$ is a necessary, but not sufficient, condition for it to be automatically regarded as developing mathematical knowledge. Consequently, two further quantitative measures are required to determine whether or not apps are appropriate.

\section{Process Two - Modified Bos Format scores}

The results from the second of the qualitative measures, the modified Bos format scale, also reflected the poor quality of most of the apps overall. Just over half of the apps $(28 / 53)$ scored more than $50 \%$ and only 17 of the apps (see Table 7) scored either a 10, indicating that they were IMO (two apps), or an 8 , indicating they were VM (15 apps).

Table 7

Apps Evaluated as IMO or VM

\begin{tabular}{rccc}
\hline Name of App & Score & Name of App & Score \\
\hline Coordinate Geometry & $\mathbf{1 0}$ & Numberkiz Geo & $\mathbf{8}$ \\
\hline
\end{tabular}




\begin{tabular}{lclc}
\hline Geometry 2D Pad & $\mathbf{1 0}$ & Symmetry Draw & $\mathbf{8}$ \\
Attribute Blocks & $\mathbf{8}$ & Transformations (Investigate) & $\mathbf{8}$ \\
Shapes - 3D Geometry & $\mathbf{8}$ & Geometry - Explore Math & $\mathbf{8}$ \\
Shapes and Colors & $\mathbf{8}$ & Simitri & $\mathbf{8}$ \\
Pattern Shapes & $\mathbf{8}$ & Hands-on Maths Geoboard & $\mathbf{8}$ \\
Montessori Geometry & $\mathbf{8}$ & Drawing the Math & $\mathbf{8}$ \\
Isometry Manipulative & $\mathbf{8}$ & Transformation Trainer & $\mathbf{8}$ \\
Geoboard (Math Learning) & $\mathbf{8}$ & Overall Mean for 53 apps & $\mathbf{7 . 3 1}$ \\
\hline
\end{tabular}

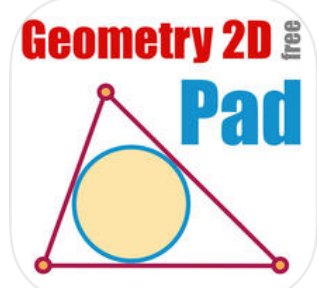

Figure 3. Geometry 2D Pad - A top scoring app on the Haugland Scale.

There were a further 11 apps which scored a 6 (drill and practice) with the resultant diminished value in terms of their usefulness. In addition, only 3 of these 11 (GeoEng, Jungle Geometry and Geometry for Kids - see Figure 3) scored above 30/50 for the total score overall (see Table 11). This is an indication that, although many of the drill and practice games scored well on both the Haugland scale and Bos' game format, they generally scored poorly on the three measures of pedagogical, mathematical or cognitive fidelity.

Consequently, the eight drill and practice apps scoring less than 30/50 overall are not recommended for classroom use, except perhaps for review purposes, once conceptual and procedural knowledge has been well established.

It is the case that the game format categories of VM and IMO are inflating the overall score of a number of the apps. Many of the apps deemed to be VM as per Bos' (2009) definition are only minimally manipulative (i.e., only one component of the app), or are manipulatives in a way that is not likely to be conducive to student learning (e.g., rotating a shape by pushing an icon with a circular arrow on it). For example, the apps Drawing the Math and Transformation Trainer both were assessed as VM; however, they both scored unfavorably on the Haugland scale (4/10 and 5/10 respectively) and so are considered inappropriate, or only barely appropriate, for young students. This is a limitation in both Bos' categorization (VM are considered to be of medium-high fidelity) and subsequently a limitation in this research, as they have been allocated a score of 8 out of 10 in keeping with Bos' original schema of medium-high fidelity. What is needed in future research using the game format schema, is a mechanism for identifying the degree to which an app is a VM. In this way, apps with limited opportunities for manipulation (e.g., Drawing the Math), or an app where manipulation is possible but not supportive of conceptual development due to an imprecise link between manipulation and conceptual development (e.g., Transformation Trainer), are not automatically considered as medium-high fidelity in Bos' schema or as scoring an 8 in my adaption of this schema.

\section{Process Three - Three Fidelities Scores}

Discussed in the following sections are (a) findings based on the levels of app quality according to each of the three fidelities, (b) an analysis of the spread of scores across the three fidelities, and finally, (c) an indication of seven apps which scored above 6/10 for each of the three fidelities indicating a high level of appropriateness. However, in order to 
contextualize the use of the three fidelity measures in relation to Australian content, it is worthwhile to present data on how well the apps correlated their content with the expectations of the Australian Curriculum (which largely reflects similar US and UK mathematics content). Table 8 indicates the number of apps that incorporated elements of the Australian Curriculum: Mathematics content.

Table 8

Number of Apps Providing Different Types of Australian Curriculum Content\#

\begin{tabular}{cccc}
\hline Sub-Strand / concepts & No. of apps & Sub-strand | concepts & No. of apps \\
\hline Lines (1D) & 16 & Slide (Translate) & 10 \\
Shapes (2D) & 31 & Flip (Reflect) & 21 \\
Objects (3D) & 17 & Turn (Rotate) & 16 \\
Angles & 15 & Dilations & 6 \\
\hline
\end{tabular}

Note: Total app count exceeds 53 as a number of apps include more than one type of content and are therefore counted more than once. \# Pythagoras and trigonometry is only introduced in Australian secondary schools and so was beyond the scope of this review.

A number of apps (e.g., Simitri) focused solely on one content area; however, many others covered content from two or more areas (e.g., EZ Geometry or Jungle Geometry). This is not always an advantage as broad coverage often meant shallow conceptual development and less classroom usefulness since only one section of the app was appropriate for any particular level. Shape content was very common as many of the apps were targeted at foundation and early years students (5-8 years old). Unfortunately, many of these "shapes apps" were very basic and only included naming of the shapes or very simple matching exercises. Reflections was the most common of the four major transformations presented in apps, perhaps because reflections are more easily represented than either rotational symmetry or translations. Angles and 1D Geometry apps were common; however, this is a result of a large number of quiz apps (largely concerning geometric reasoning) rather than the presence of apps that develop conceptual understanding of angles or 1D Geometry.

Table 9 provides a breakdown of the number of apps scoring 6 or more in each of the three fidelities. Although this looks like a healthy number of apps (42) scoring at least one 6, this is not the case, as many of the better apps scored a 6 or more in two or three categories and these apps are counted more than once.

Table 9

Number of Apps Scoring 6 or More in Respective Fidelities

\begin{tabular}{lccc}
\hline Type of fidelity & $\begin{array}{c}\text { Number of apps } \\
(\mathbf{n = 5 3 )}\end{array}$ & $\begin{array}{c}\text { Percentage (to } \\
\text { nearest 0.1) }\end{array}$ & Average score / 10 \\
\hline Pedagogical & 21 & $39.6 \%$ & 4.9 \\
Mathematical & 13 & $24.5 \%$ & 4.3 \\
Cognitive & 8 & $15.1 \%$ & 3.7 \\
$\quad$ Overall Average Score for apps on the three measures / 30 & 12.9 \\
\hline
\end{tabular}

Overall, 26 of the 53 apps failed to score a 6 in any category; the average score of the 53 apps was 12.9/30; and none of the three fidelity categories scored above $50 \%$ overall. As was the case with the Haugland scale scores, these low scores are a further indication that there are a large number of Geometry apps, categorized as educational in the iTunes store, which do not meet even a very low benchmark for classroom appropriateness. Figure 4 provides a visual summary of the scores of the apps on the fidelity subtotal (i.e., combined pedagogical, mathematical, and cognitive fidelity scores). As might have been anticipated, given than many apps are instructional and focus on declarative or procedural knowledge 
(Larkin, 2014), the apps which were of some use tended to score well on the pedagogical fidelity dimension, less well in terms of the quality of the mathematics they contain, and generally poorly in their ability to assist cognitive development. This again mirrors the generally poor level of conceptual knowledge developed by apps reported in the earlier research.

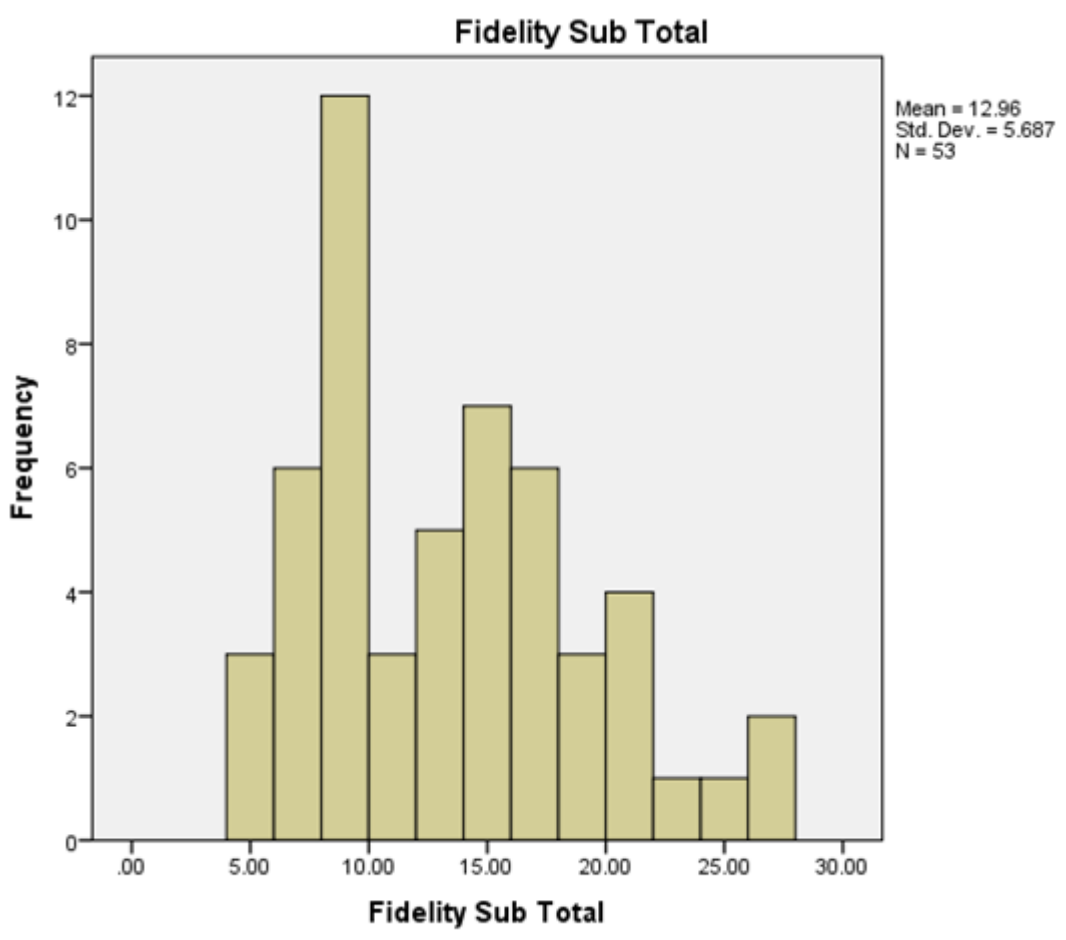

Figure 4. Three fidelities subtotal.

The apps scored reasonably well in terms of pedagogical fidelity because this is the easiest of the categories for app designers (with likely low levels of mathematics education experience) to mimic. Many of the apps met one of the criteria, namely they were easy to use without instruction, and many of them partially met the criteria of appropriateness of activity without necessarily doing anything more than could be easily replicated with an IWB, physical manipulatives, or even pen and paper. Many of them incorporated multiple-choice quizzes which may serve some use as review exercises. This is particularly the case where they draw from a large bank of questions, do not allow multiple guesses, or allow results to be emailed (e.g., Kids Math-Angle Geometry and Symmetry School Learning). Mathematical fidelity issues generally related to incorrect naming or classification of shapes and objects (e.g., diamonds instead of rhombuses, cubes not being considered as prisms etc); use of prototype orientations and shapes (only three apps focused on non-prototypical shapes Cyberchase Quest, Maths Geometry, and Shapes MyBlee); and a lack of connection to any notion of real-world application of mathematics (minor exceptions to this include Geometry 4 Kids and Simitri).

Low cognitive fidelity is problematic in terms of classroom use as this relegates many of the apps to only being useful as review activities or for rote learning. The majority of apps did not meet the criteria for supporting cognitive development. Despite being technically capable, most apps only provided static representations and, where dynamic representations were used, they did not mimic the physical activity of turning or sliding or flipping but used arrows or numbers to direct the transformations (noteworthy exceptions were Squares and Colors and Shapes MyBlee). In addition, very few apps allowed opportunity for students to 
create patterns and develop their own conjectures regarding shapes, objects, angles or transformations. Although the technology present in the device allows for dynamic representations of shapes, objects and angles (e.g., Cyberquest and Isometry Manipulatives), by far the majority of the apps did not make use of this technology and consequently did not replicate the real-world experience of the geometry they were attempting to represent. This is a serious shortcoming in the ability of these apps to encourage Geometry conceptual development.

Despite the comments above, it is not all negative as there are some apps that perform well (see Tables 10 and 11 and Figure 5).

Table 10

Apps that Scored 6 or More on each of the Three Fidelities

\begin{tabular}{|l|c|c|c|c|}
\hline \multicolumn{1}{|c|}{ App name } & Pedagogical & Mathematical & Cognitive & Total \\
\hline Co-ordinate Geometry & 9 & 8 & 9 & 26 \\
\hline Transformations & 9 & 8 & 9 & 26 \\
\hline Attribute Blocks & 8 & 8 & 8 & 24 \\
\hline Shapes - 3D Geometry & 9 & 6 & 8 & 23 \\
\hline Shapes and Colors & 7 & 6 & 7 & 20 \\
\hline Pattern Shapes & 8 & 6 & 6 & 20 \\
\hline Isometry Manipulative & 7 & 6 & 6 & 19 \\
\hline
\end{tabular}
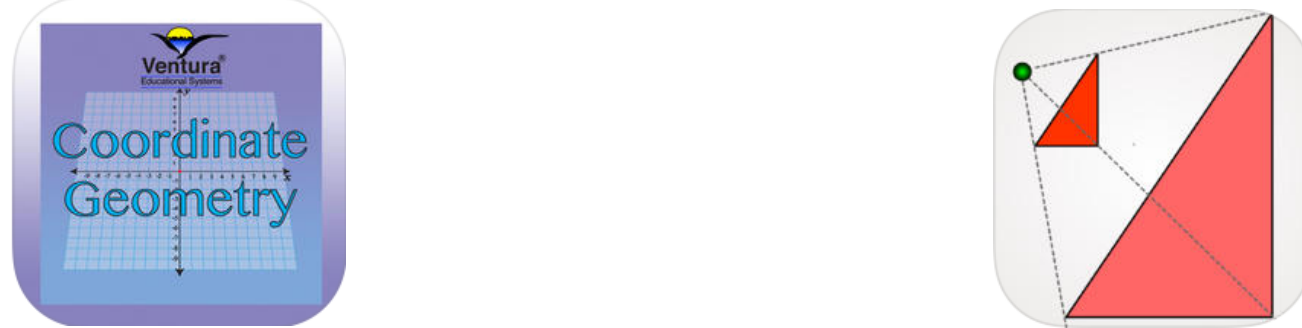

Figure 5. Coordinate Geometry \& Transformations - equal top scoring fidelity apps.

Of the apps reviewed, seven of them (13\% of the total apps reviewed) scored 6 or more out of 10 for each of the three fidelities. These are clearly the apps that teachers should be utilizing in their classroom practice. What is interesting here is that apart from the top three, even the better apps were inconsistent in meeting the three fidelity standards as four of the seven scored at least one 6 with two of these four scoring two 6s. This level of inconsistency mirrors the findings of Moyer-Packenham et al. (2014) and Moyer-Packenham and Suh (2012) in relation to virtual manipulatives and can be seen in the wide range of scores even among the top half of the apps (see Table 11 and Figure 6). In both of the research studies cited, the authors noted multiple affordances within each virtual manipulative such that one or more of these affordances may be more influential and beneficial for student learning. An example of this is the Isometry manipulative, where one component of the app is extremely beneficial while the second component is likely to undermine student learning. This inconsistency becomes more apparent the further down the list of scores you proceed. For example, Montessori Geometry $(9,6,5)$ scored equal to or higher than three of the apps listed in the top seven but was relatively poor in terms of cognitive development. Three other apps scored highly in pedagogical and mathematical fidelity but poorly in terms of cognitive development (GeoEng - 8, 6, 5; Geometry 4 Kids - 8, 6, 3; and Geometry Explore - 6, 6, 4). It is worth noting that only one app (Simitri - 4, 9, 8) scored very poorly in pedagogical fidelity, but very highly in mathematics and cognitive 
fidelity. This indicates that this app, with correct scaffolding from the teacher, is potentially very useful for developing high-level mathematical and cognitive fidelity.

Table 11

Ranked List of 21 Apps Scoring More than 50\% Overall and 50\% on Each of the Haugland Scale, Game Format and Three Fidelities*

\begin{tabular}{|c|c|c|c|c|c|c|c|c|c|c|}
\hline \multirow[b]{2}{*}{ Application Name } & \multirow[b]{2}{*}{$\begin{array}{c}\text { App } \\
\text { Format } \\
/ 10\end{array}$} & \multicolumn{4}{|c|}{ Haugland Cluster /10 } & \multicolumn{4}{|c|}{ Fidelity / 30} & \multirow[b]{2}{*}{$\begin{array}{c}\text { Total } \\
\text { Score } \\
\text { / } 50\end{array}$} \\
\hline & & $\begin{array}{c}\text { Child- } \\
\text { Centered }\end{array}$ & $\begin{array}{c}\text { Design } \\
\text { Features }\end{array}$ & $\begin{array}{c}\text { Maths } \\
\text { Learning }\end{array}$ & $\begin{array}{l}\text { Haugland } \\
\text { Total / } 10\end{array}$ & $\begin{array}{c}\text { Pedagogical } \\
/ 10\end{array}$ & $\begin{array}{c}\text { Mathematical } \\
/ 10\end{array}$ & $\begin{array}{c}\text { Cognitive } \\
/ 10\end{array}$ & $\begin{array}{c}\text { Fidelity } \\
\text { Sub } \\
\text { Total } \\
\text { / } 30\end{array}$ & \\
\hline Coordinate Geometry (Ventura) & 10 & 4 & 2 & 2 & 8 & 9 & 8 & 9 & 26 & 44 \\
\hline Attribute Blocks & 8 & 4 & 2.5 & 2.5 & 9 & 8 & 8 & 8 & 24 & 41 \\
\hline Transformations (Investigate) & 8 & 2 & 1.5 & 3 & 6.5 & 9 & 8 & 9 & 26 & 40.5 \\
\hline Shapes - 3D Geometry & 8 & 3.5 & 2 & 2.5 & 8 & 9 & 6 & 8 & 23 & 39 \\
\hline Shapes and Colors & 8 & 4 & 2 & 2 & 8 & 7 & 6 & 7 & 20 & 36 \\
\hline Pattern Shapes & 8 & 4 & 2 & 2 & 8 & 8 & 6 & 6 & 20 & 36 \\
\hline Geometry (Monessori) & 8 & 4 & 3 & 1 & 8 & 9 & 6 & 5 & 20 & 36 \\
\hline Simitri & 8 & 2 & 1.5 & 2.5 & 6 & 4 & 9 & 8 & 21 & 35 \\
\hline Isometry Manipulative & 8 & 3.5 & 2 & 2 & 7.5 & 7 & 6 & 6 & 19 & 34.5 \\
\hline GeoEng (Patterns) & 6 & 4 & 3 & 1 & 8 & 8 & 6 & 5 & 19 & 33 \\
\hline Geoboard (Math Learning Centre) & 8 & 4 & 2 & 1.5 & 7.5 & 7 & 5 & 5 & 17 & 32.5 \\
\hline Numberkiz Geo & 8 & 4 & 1.5 & 2 & 7.5 & 8 & 5 & 4 & 17 & 32.5 \\
\hline Jungle Geometry & 6 & 4 & 3 & 1 & 8 & 8 & 5 & 5 & 18 & 32 \\
\hline Shapes (MyBlee) & 6 & 4 & 2.5 & 2.5 & 9 & 7 & 5 & 5 & 17 & 32 \\
\hline Geometry - Explore Math (VENTURA) & 8 & 3.5 & 2.5 & 0.5 & 6.5 & 6 & 6 & 4 & 16 & 30.5 \\
\hline Geometry4Kids & 6 & 3.5 & 2.5 & 1 & 7 & 8 & 6 & 3 & 17 & 30 \\
\hline Symmetry Draw & 8 & 3 & 1.5 & 2.5 & 7 & 6 & 4 & 5 & 15 & 30 \\
\hline Shape Rotate & 6 & 4 & 2 & 1 & 7 & 6 & 5 & 5 & 16 & 29 \\
\hline Sym Shuffle & 6 & 4 & 2.5 & 1.5 & 8 & 6 & 4 & 4 & 14 & 28 \\
\hline Symmetry School Learning & 6 & 4 & 1 & 1.5 & 6.5 & 5 & 5 & 5 & 15 & 27.5 \\
\hline Geometry 2D Pad & 10 & 1 & 1 & 2 & 4 & 2 & 7 & 4 & 13 & 27 \\
\hline Butterfly Brunch & 6 & 3 & 1 & 1 & 5 & 5 & 5 & 5 & 15 & 26 \\
\hline Shapes and Geometry Skill Builders & 6 & 2.5 & 2.5 & 1 & 6 & 7 & 4 & 3 & 14 & 26 \\
\hline Math Geometry & 4 & 3 & 2 & 1 & 6 & 6 & 5 & 4 & 15 & 25 \\
\hline
\end{tabular}

* Geometry 2D Pad scored highly in the game format and in mathematics fidelity and scored 27 overall but is excluded due to a below 50\% score in the Haugland scale. Math Geometry scored 25 overall but is excluded due to a below $50 \%$ score in the Bos game format.

Table 11 provides further details to assist classroom teachers with the selection of appropriate apps. Each of the apps listed in Table 11 scored a "pass" mark of $50 \%$ in terms of overall score and $50 \%$ on each of the three quantitative measures. Heeding the earlier caution of Moyer-Packenham et al. (2014) and Moyer-Packenham and Suh (2012), these apps at least meet a benchmark of quality but need to be used thoughtfully by classroom teachers in their mathematics classrooms. 


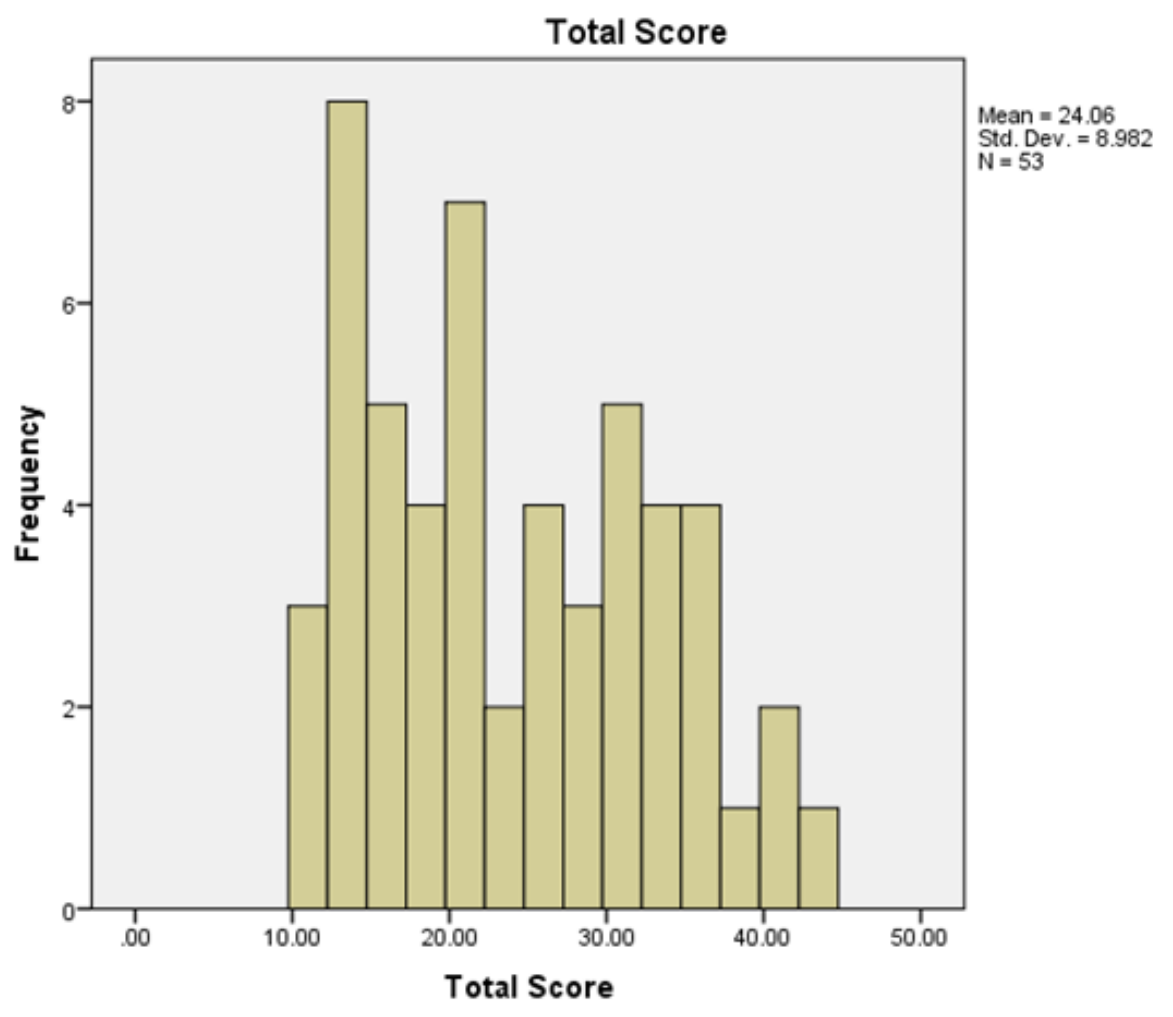

Figure 6. Histogram of overall scores for 53 apps.

\section{Limitations and Conclusion}

A limitation of any research reviewing apps is an inherent consequence of the nature of the iTunes App Store. Firstly, the sheer number and method of labelling apps means that there may be useful Geometry apps not reviewed. Secondly, the iTunes store is a moveable feast as apps are generated, renamed, relocated, or removed on a daily basis. Therefore, it is not possible to claim that all quality Geometry apps have been critiqued. Furthermore, it is important for the continued currency of the reviews that other teachers and researchers add to the database of reviews.

However, within the constraints noted above, it is clearly the case that, other than the top three apps, teachers need to decide the exact instructional purpose for using the app and then look at the individual fidelity scores of the app to locate one that meets that specific purpose. In this manner, Montessori Geometry would be most appropriate to use for review purposes but not appropriate in terms of developing conceptual or mathematical fidelity.

This research has indicated that, although many Geometry apps are quite poor in terms of their fidelity, it is, to return to the question posed in the title, certainly not a futile exercise to use some of them in mathematics classrooms. Many of the apps do go beyond the rather cynical "tracing use" hinted at in the title of this chapter. The use of the Haugland scale provides an initial filter on the appropriateness of the apps for young students. In its current format, the Bos game format score provides limited information regarding quality, and is not accurate enough to be of much assistance. The key measure for teachers to use in gauging the mathematical quality of an app is the modified three fidelities scoring rubric created for this research, as apps that scored well in these measures also scored highly in the Haugland scale and game format and thus demonstrate great potential for enhancing student learning. It is hoped that this research will be useful for teachers when selecting apps to support mathematics learning. Future research will investigate the use of a selected number of quality Geometry apps in Australian and Canadian classrooms. 


\section{Acknowledgments}

This chapter develops further a paper presented at MERGA38, 2015. The author would like to sincerely thank Doctor Todd Milford (University of Victoria, Canada) for his assistance with the quantitative data analysis in this chapter.

\section{References}

148AppsBiz. (2015). App store metrics. Retrieved from http://148apps.biz/app-store-metrics/

Beavis, C., Muspratt, S. \& Thompson, R. (2015) 'Computer games can get your brain working': student experience and perceptions of digital games in the classroom, Learning, Media and Technology, 40:1, 21-42, DOI: 10.1080/17439884.2014.904339

Bos, B. (2009). Technology with cognitive and mathematical fidelity: What it means for the Math classroom. Computers in the Schools, 26(2), 107-114. doi: $10.1080 / 07380560902906088$

Bos, B. (2011). Professional development for elementary teachers using TPACK. Contemporary Issues in Technology and Teacher Education, 11(2), 167-183.

Burns, B. A., \& Hamm, E. M. (2011). A comparison of concrete and virtual manipulative use in third- and fourth-grade Mathematics. School Science and Mathematics, 111(6), 256-261. doi: 10.1111/j.1949-8594.2011.00086.x

Calder, N. (2015). Apps: Appropriate, applicable and appealing? In T. Lowrie \& R. Jorgensen (Eds.), Digital games and mathematics learning: Potential, promises and pitfalls. Dordrecht, The Netherlands: Springer.

Carbonneau, K. J., Marley, S. C., \& Selig, J. (2013). A meta-analysis of the efficacy of teaching Mathematics with concrete manipulatives. Journal of Educational Psychology, 105(2), 380-400. doi: 10.1037/a0031084

Chang, W.-L., Yuan, Y., Lee, C.-Y., Chen, M.-H., \& Huang, W.-G. (2013). Using Magic Board as a teaching aid in third grader learning of area concepts. Educational Technology \& Society, 16(2), 163-173.

Clements, D. H., \& Battista, M. T. (1992). Geometry and spatial reasoning. In D. A. Grouws (Ed.), Handbook of research on Mathematics teaching and learning (pp. 420-464). New York: Macmillan.

Dick, T. P. (2008). Fidelity in technological tools for Mathematics education. In G. W. Blume \& M. K. Reid (Eds.), Research on technology and the teaching and learning of Mathematics: Volume 2. Cases and perspectives (pp. 333-339). Charlotte, N.C.: Information Age Publishing.

Haugland, S. (1999). Computers and young children: The newest software that meets the developmental needs of young children. Early Childhood Education Journal, 26(4), 245-254.

Haugland, S. W., \& Ruız, E. A. (2002). Computers and Young Children Empowering children with technology: Outstanding developmental software for 2002. Early Childhood Education Journal, 30(2), 125-132.

Highfield, K., \& Mulligan, J. (2007). The Role of Dynamic Interactive Technological Tools in Preschoolers' Mathematical Patterning. In Proceedings of the 30th annual conference of the Mathematics Education Research Group of Australasia, Hobart.

Larkin, K. (2013). Mathematics Education. Is there an App for that? In V. Steinle, L. Ball \& C. Bardini (Eds.), Mathematics education: Yesterday, today and tomorrow (Proceedings of the 36th annual conference of the Mathematics Education Research Group of Australasia) (pp. 426-433). Melbourne, VIC: MERGA.

Larkin, K. (2014). IPad Apps that promote mathematical knowledge? Yes, they exist! Australian Primary Mathematics Classroom, 19(2), 28-32. 
Larkin, K. (2015). The Search for Fidelity in Geometry Apps: An Exercise in Futility? In M. Marshman, V. Geiger \& A. Bennison (Eds.) Mathematics Education in the Margins. (Proceedings of the 38th Annual Conference of the Mathematics Education Research Group of Australasia). Sunshine Coast, QLD: MERGA

Larkin, K. (2015) “An App! An App! - My Kingdom for an App”: An 18 month quest to determine whether apps support mathematical knowledge building. In T. Lowrie \& R. Jorgensen (Eds) Digital games and mathematics learning: Potential, promises and pitfalls. Springer Press

Manches, A., \& O'Malley, C. (2012). Tangibles for learning: A representational analysis of physical manipulation. Personal and Ubiquitous Computing, 16(4), 405-419. doi: http://dx.doi.org/10.1007/s00779-011-0406-0

Moyer-Packenham, P. S., Salkind, G., \& Bolyard, J. J. (2008). Virtual manipulatives used by K-8 teachers for mathematics instruction: Considering mathematical, cognitive, and pedagogical fidelity. Contemporary Issues in Technology and Teacher Education, $8(3), 202-218$.

Moyer-Packenham, P. S., Shumway, J. F., Bullock, E., Tucker, S. I., Anderson-Pence, K., Westenskow, A., ... Jordan, K. (2014). Young children's learning performance and efficiency when using virtual manipulative mathematics iPad apps. Paper presented at the National Council of Teachers of Mathematics Research Conference (NCTM), New Orleans, Louisiana.

Moyer-Packenham, P. S., \& Suh, J. M. (2012). Learning Mathematics with technology: The influence of virtual manipulatives on different achievement groups. Journal of Computers in Mathematics and Science Teaching, 31(1), 39-59.

Muijs, D. (2011). Doing quantitative research in education with $\operatorname{SPSS}\left(2^{\text {nd }}\right.$ ed.). London: Sage.

Özel, S. (2012). Learning rational numbers: An experimental multi-model representation approach via technology. Mediterranean Journal for Research in Mathematics Education, 11(1-2), 59-79.

Puchner, L., Taylor, A., O'Donnell, B., \& Fick, K. (2008). Teacher learning and Mathematics manipulatives: A collective case study about teacher use of manipulatives in elementary and middle school Mathematics lessons. School Science and Mathematics, 108(7), 313-325. doi: 10.1111/j.1949-8594.2008.tb17844.x

Reimer, K., \& Moyer, P. S. (2005). Third-graders learn about fractions using virtual manipulatives: A classroom study. The Journal of Computers in Mathematics and Science Teaching, 24(1), 5-25.

Rosen, D., \& Hoffman, J. (2009). Integrating concrete and virtual manipulatives in early childhood mathematics. Young Children, 64(3), 26-29, 31-33.

Suh, J., \& Moyer, P. S. (2007). Developing students' representational fluency using virtual and physical algebra balances. The Journal of Computers in Mathematics and Science Teaching, 26(2), 155-173.

Uribe-Flórez, L. J., \& Wilkins, J. L. M. (2010). Elementary school teachers' manipulative use. School Science and Mathematics, 110(7), 363-371. doi: 10.1111/j.19498594.2010.00046.x

Zbiek, R. M., Heid, M. K., Blume, G. W., \& Dick, T. P. (2007). Research on technology in Mathematics education: A perspective of constructs. In F. K. Lester (Ed.), Second handbook of research on Mathematics teaching and learning (pp. 1169-1207). Charlotte, N.C.: National Council of Teachers of Mathematics. 
Appendix- Scoring Sheet used to evaluate the 53 apps

Title:

Reviewer:
HAUGLAND DEVELOPMENTAL SOFTWARE SCALE (Adapted)

Review Date:

Recommended Age Range:

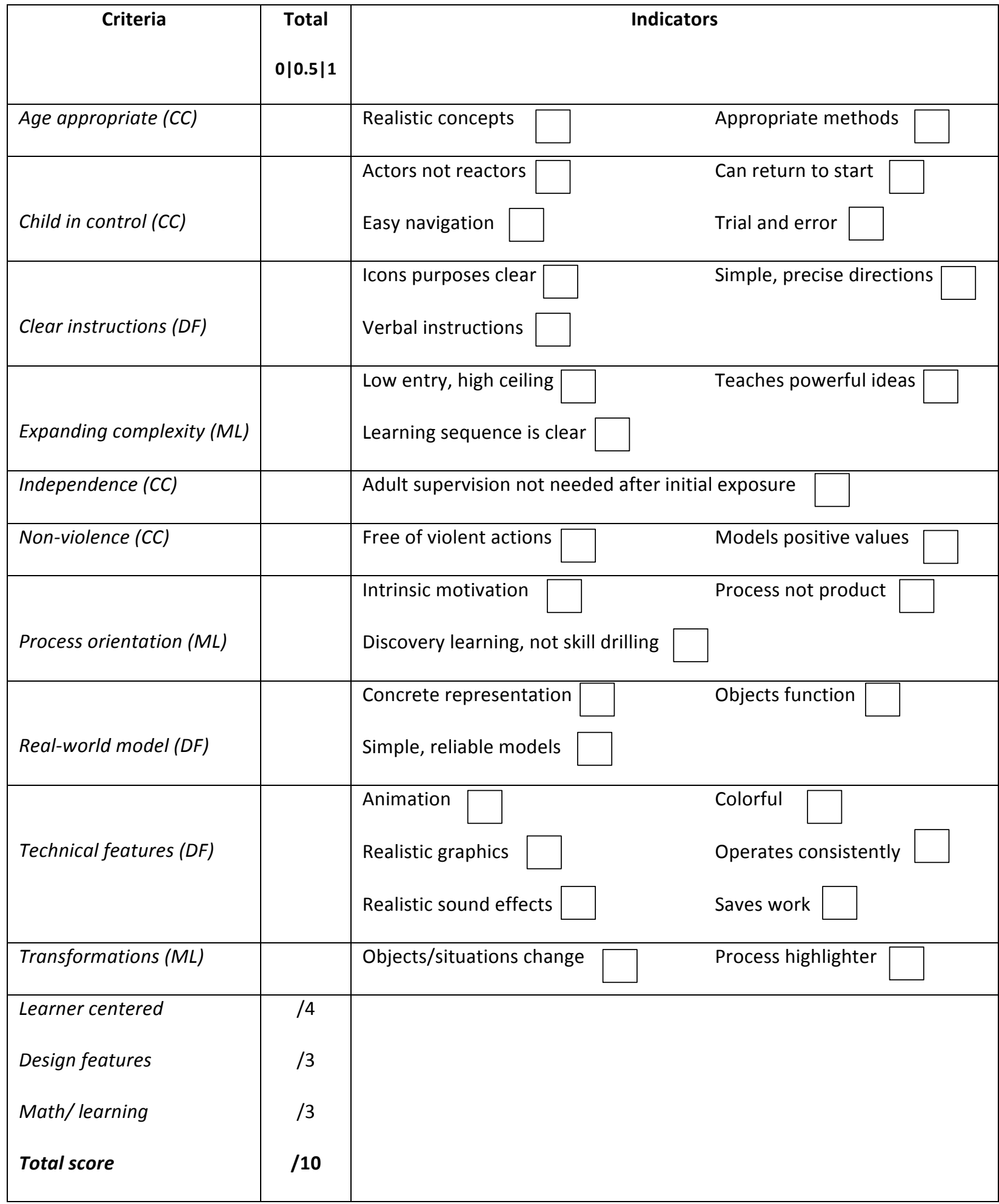

Reviewer Comments: 
App Name:

Mathematics Strand Content:

\section{Geometry Apps Scoring Sheet}

Date Reviewed: Nov 14, 014

Year Level:

App description from iTunes Store: This app

Reviewer summary of App: This app

App format (adapted from Bos, 2009) (Circle most relevant format)

\begin{tabular}{|c|c|c|c|}
\hline Generates & Informational & Quizzes / tests & \multirow{2}{*}{$/ \mathbf{1 0}$} \\
calculations $/ \mathbf{1}$ & $\mathbf{3}$ & $/ \mathbf{4}$ & \\
\cline { 1 - 3 } $\begin{array}{c}\text { Drill \& practice } \\
\text { games } / \mathbf{6}\end{array}$ & $\begin{array}{c}\text { Virtual manipulative } \\
\mathbf{8}\end{array}$ & $\begin{array}{c}\text { Mathematics objects } \\
\mathbf{1 0}\end{array}$ & \\
\hline
\end{tabular}

Themed Haugland Scale Score

\begin{tabular}{|c|c|c|c|}
\hline Learner centered /4 & Design features $/ \mathbf{3}$ & $\begin{array}{c}\text { Mathematical learning } \\
\mathbf{3}\end{array}$ & $/ \mathbf{1 0}$ \\
\hline
\end{tabular}

Pedagogical Fidelity (Circle appropriate score)

\begin{tabular}{|llllllllllll|l|}
\hline \multirow{1}{\longleftrightarrow}{} & 2 & 3 & 4 & 5 & 6 & 7 & 8 & 9 & 10 & 11 & 12 & $/ \mathbf{1 2}$ \\
\hline
\end{tabular}

Mathematical Fidelity (Circle appropriate score)

\begin{tabular}{|c|c|c|c|c|c|c|c|c|c|c|c|c|}
\hline & & & & & & & & & & & $\rightarrow$ & \multirow[t]{2}{*}{112} \\
\hline 1 & 2 & 3 & 4 & 5 & 6 & 7 & 8 & 9 & 10 & 11 & 12 & \\
\hline
\end{tabular}

Cognitive Fidelity (Circle appropriate score)

\begin{tabular}{|c|c|c|c|c|c|c|c|c|c|c|c|c|}
\hline \multirow{2}{*}{$\leftarrow$} & & & & & & & & & & & $\rightarrow$ & \multirow[t]{2}{*}{$/ 12$} \\
\hline & 2 & 3 & 4 & 5 & 6 & 7 & 8 & 9 & 10 & 11 & 12 & \\
\hline \multicolumn{12}{|c|}{ Overall Comment and Score: This app } & $/ 50$ \\
\hline
\end{tabular}

